Article

\title{
Comparative Phytochemical, Antioxidant and Haemostatic Studies of Preparations from Selected Vegetables from Cucurbitaceae Family
}

\author{
Agata Rolnik ${ }^{1, *}$, Iwona Kowalska ${ }^{2}$, Agata Soluch ${ }^{2}$, Anna Stochmal ${ }^{2}$ and Beata Olas ${ }^{1}$ (D) \\ 1 Department of General Biochemistry, Faculty of Biology and Environmental Protection, University of Łódź, \\ 90-236 Łódź, Poland; beata.olas@biol.uni.lodz.pl \\ 2 Department of Biochemistry and Crop Quality, Institute of Soil Science and Plant Cultivation, State Research \\ Institute, 24-100 Puławy, Poland; ikowalska@iung.pulawy.pl (I.K.); asoluch@iung.pulawy.pl (A.S.); \\ asf@iung.pulawy.pl (A.S.) \\ * Correspondence: agata.rolnik@unilodz.eu
}

Received: 20 August 2020; Accepted: 18 September 2020; Published: 21 September 2020

\begin{abstract}
The aim of this study was to provide detailed insight into the chemical composition and activity of five cucurbit vegetable preparations (pumpkin, zucchini, cucumber, white and yellow pattypan squash), each containing various phytochemical compounds with potential use against oxidative stress induced by the hydroxyl radical donors in human plasma in vitro. We studied the antiradical capacity of vegetable preparations using the DPPH (2,2-diphenyl-1-picrylhydrazyl) method. As oxidative stress may induce changes in hemostasis, our aim included the determination of their effect on three selected hemostatic parameters of plasma, which are three coagulation times: PT (prothrombin time), APTT (activated partial thromboplastin time) and TT (thrombin time). However, none of used vegetable preparations changed APTT, PT or TT compared to the control. The phytochemical composition of the tested preparations was determined by UPLC-ESI-QTOF-MS. In our in vitro experiments, while all five tested preparations had antioxidant potential, the preparation from yellow pattypan squash showed the strongest potential. All cucurbit vegetable preparations inhibited lipid peroxidation. Only zucchini did not have an effect on protein carbonylation and only yellow pattypan squash inhibited thiol oxidation. The antioxidant activity of cucurbits appears to have triggered significant interest in multiple applications, including CVDs (cardiovascular diseases) associated with oxidative stress, which can be treated by supplementation based on these vegetables.
\end{abstract}

Keywords: oxidative stress; plasma; coagulation; UPLC-ESI-QTOF-MS analysis; Cucurbitaceae family

\section{Introduction}

Lifestyle factors, including nutrition, play an important role in the etiology and treatment of cardiovascular diseases (CVDs) [1]. Recent results have demonstrated that certain vegetables (for example onion, garlic, tomato and beetroot) and their products may act as mediators in the prevention and treatment of cardiovascular diseases by various mechanisms [1-4]. The cardioprotective actions of vegetables may include lowering of blood pressure, improving endothelial function, modifying lipid metabolism and reducing oxidative stress [2,3]. The regular intake of vegetable products rich in phenolic compounds is associated with a reduced risk of cardiovascular diseases [1,4]. However, the effect of vegetables from the Cucurbitaceae family on parameters of oxidative stress and hemostasis is not always well documented. In addition, the chemical components of preparations (for example extracts and fractions) isolated from these vegetables have not been adequately described.

The Cucurbitaceae family is a large group of crops, with 800 species. The most popular cucurbits are pumpkin, cucumber, melon and watermelon. They are cultivated and consumed in various parts 
of the world. Moreover, they are used in traditional medicine, for example in China, India, Mexico and Brazil [5]. Some results demonstrate that these vegetables have hepatoprotective, cardiovascular and anti-inflammatory properties [6,7]. These actions are commonly linked with chemical components. They are also rich in different phytochemicals [8].

It is known that polyphenol-rich extracts may alleviate the negative impact of oxidative stress and hemostasis [9]. Cucurbit preparations were investigated in the present work (in vitro model). This study aimed to investigate the in vitro protective effects of five cucurbit vegetable preparations: pumpkin (Cucurbita pepo; fruit without seeds), zucchini (Cucurbita pepo convar. giromontina; fruit with seeds), cucumber (Cucumis sativus; fruit with seeds), white pattypan squash (Cucurbita pepo var. patisoniana; fruit without seeds) and yellow pattypan squash (Cucurbita pepo var. patisoniana; fruit without seeds). We measured different parameters of oxidative stress: lipid peroxidation determined by thiobarbituric acid reactive substances (TBARS); thiol group level; protein carbonylation; oxygen radical antioxidant capacity (ORAC); and total antioxidant capacity of plasma. In addition, we also studied the antiradical capacity of preparations from cucurbit vegetables using the DPPH (2,2-diphenyl-1-picrylhydrazyl) test. As oxidative stress may induce changes in hemostasis [10], another aim of our experiments was to determine the effect of the five vegetable preparations on three selected hemostatic parameters of human plasma: activated partial thromboplastin time (APTT), prothrombin time (PT), and thrombin time (TT) in an in vitro model.

\section{Results}

\subsection{Chemical Characteristic of Vegetable Preparations}

The information on the occurrence of phytochemicals in the five cucurbit vegetable preparations with their UPLC-ESI-QTOF-MS data is shown in Table 1. A total of 36 phytochemicals were characterized, and most could be identified by comparing their retention times, MS spectra and MS/MS fragmentation and literature data [10-15]. As shown by the UPLC-ESI-QTOF-MS analysis, the five cucurbit vegetable preparations differed in their final qualitative chemical composition (Figure 1A-E), except for the two pattypan squash varieties (Figure 1B,C), whose composition was somewhat similar, with corresponding base-peak chromatograms (BPC) in the negative ionization mode of the five tested preparations. Among the identified metabolites were analytes belonging to different compound classes. The vast majority were representatives of groups such as phenylethanoid glycosides, flavonoids, fatty acids and lipids. The last class of compounds occurred in a significant amount in all the analyzed profiles and was identified as glycerophospholipids. The pumpkin (Figure 1D) and cucumber (Figure 1E) preparations showed the smallest phytochemical diversity. In these extracts, among the phenols, derivatives of kaempferol and synapic acid were identified. The extracts of zucchini (Figure 1A), white pattypan squash (Figure 1C) and yellow pattypan squash (Figure 1B) also contained phenolic compounds known as phenylethanoids, all of them occurring in the form of glycosides. Among the more known flavonoids, quercetin-3-O-rutinoside (rutin), 7-methylquercetin-3-galactoside-6" -rhamnoside-3" "'-rhamnoside (xanthorhamnin), methyl 5-methoxy2-[(6-O-pentopyranosylhexopyranosyl)oxy]benzoate derivative (primulaverin), isorhamnetin 3-Orutinoside (narcissin), hesperetin 7-O-(2",6"-di-O- $\alpha$-rhamnopyranosyl)- $\beta$-glucopyranoside and quercetin 3,3'-dimethyl ether 7-rutinoside were identified, with all these metabolites only being found together in the extract from zucchini. Amino acids were interpreted as two compounds, L-phenylalanine glycoside located in the extracts from pumpkin, cucumber and white pattypan squash, and L-tryptophan glycoside identified in the fractions from pumpkin, zucchini and white pattypan squash. The largest amount of compounds from the group of fatty acids was detected in the most diverse phytochemical profile of zucchini i.e., all-cis-6,9,12-octadecatrienoic acid ( $\gamma$-linolenic acid) derivative, $(9 Z, 12 Z)$-octadeca-9,12-dienoic acid (linoleic acid) derivative and other not identified octadecadienoic acid derivatives. Two of the last compounds described were also present in the other four preparations. Many individual compounds were also identified, namely 
3-( $\beta$-D-glucopyranosyloxy)-2-hydroxybenzoic acid in the preparation from yellow pattypan squash; 3,4-dihydroxyphenyl-1-methyl ester-carbamic acid in the preparation from pumpkin; cinncassiol A in the preparation from white pattypan squash; secoisolariciresinol monoglucoside in the preparations from both pattypan squashes; and, as the last identified active compound, nonanedioic acid (azelaic acid) was found in the all tested preparations. 
Table 1. UPLC-ESI-QTOF-MS data of identified compounds and their presence $(+)$ in five cucurbit vegetable preparations.

\begin{tabular}{|c|c|c|c|c|c|c|c|c|c|c|}
\hline $\mathrm{Nr}$ & Rt (min) & Identified Compound & Compound Class & $\begin{array}{l}\text { [M-H], m/z, } \\
\text { ESI Neg. }\end{array}$ & $\begin{array}{l}\text { Major MS-MS } \\
\text { Fragments }\end{array}$ & Pumpkin & Cucumber & Zucchini & $\begin{array}{c}\text { White } \\
\text { Pattypan } \\
\text { Squash }\end{array}$ & $\begin{array}{c}\text { Yellow } \\
\text { Pattypan } \\
\text { Squash }\end{array}$ \\
\hline 1 & 1.14 & $\begin{array}{l}\text { 3-( } \beta \text {-D-glucopyranosyloxy)-2- } \\
\text { hydroxybenzoic acid }\end{array}$ & $\begin{array}{l}\text { benzoic acid } \\
\text { derivative }\end{array}$ & 315.071649 & 152,315 & - & - & - & - & + \\
\hline 2 & 1.47 & fructosyl L-phenylalanine & amino acid & 326.124313 & $164,236,326$ & + & + & - & + & + \\
\hline 3 & 1.87 & L-tryptophan glycoside & amino acid & 365.134743 & $116,203,275,365$ & + & - & - & - & - \\
\hline 4 & 2.45 & salicylic acid $O$-glycoside & phenolic acid & 299.077241 & 137, 299 & - & + & - & - & - \\
\hline 5 & 3.87 & zizybeoside I & $\begin{array}{l}\text { phenylethanoid } \\
\text { glycoside }\end{array}$ & 431.155861 & 147,431 & - & - & + & - & - \\
\hline 6 & 4.23 & forsythoside E (isomer I) & $\begin{array}{l}\text { phenylethanoid } \\
\text { glycoside }\end{array}$ & 461.166185 & $147,309,461$ & - & - & + & + & + \\
\hline 7 & 4.35 & cinncassiol A & diterpenoid & 381.191905 & 289,381 & - & - & - & + & - \\
\hline 8 & 4.39 & sinapic acid hexoside & phenolic acid & 431.192317 & $223,385,431$ & + & - & - & - & - \\
\hline 9 & 4.43 & hydrangeifolin I & $\begin{array}{l}\text { phenylpropanoid } \\
\text { glycoside }\end{array}$ & 415.160971 & $269,415,461$ & - & - & - & + & + \\
\hline 10 & 4.55 & shimaurinoside B & $\begin{array}{l}\text { megastigmane } \\
\text { glycosides }\end{array}$ & 381.176621 & $249,381,427$ & + & - & - & - & - \\
\hline 11 & 4.65 & kaempferol derivative & flavonoid & 450.117527 & $145,285,450$ & - & + & - & - & - \\
\hline 12 & 4.68 & primulaverin derivative & flavonoid & 475.146049 & $133,295,323,475$ & - & - & + & - & - \\
\hline 13 & 4.75 & adenostemmoic acid C & diterpenoid & 367.212612 & $287,303,367$ & - & - & - & - & + \\
\hline 14 & 5.50 & rutin & flavonoid & 609.146766 & 301,609 & - & - & + & - & - \\
\hline 15 & 5.69 & secoisolariciresinol monoglucoside & lignan & 523.217892 & $165,361,523$ & - & - & - & + & + \\
\hline 16 & 5.75 & xanthorhamnin & flavonoid & 769.219503 & $299,314,769$ & - & - & + & - & - \\
\hline 17 & 6.54 & unidentified & iridoid glycoside & 413.145347 & $269,311,351,413$ & - & - & + & + & + \\
\hline 18 & 6.88 & isorhamnetin 3-O-rutinoside & flavonoid & 623.161334 & $299,315,623$ & - & - & + & - & - \\
\hline 19 & 7.21 & azelaic acid & dicarboxylic acid & 187.097798 & 125,187 & + & + & - & - & + \\
\hline 20 & 8.41 & $\begin{array}{c}\text { hesperetin } 7-O-\left(2^{\prime \prime}, 6^{\prime \prime} \text {-di-O- } \alpha \text { - }\right. \\
\text { rhamnopyranosyl)- } \\
\beta \text {-glucopyranoside }\end{array}$ & flavonoid & 739.244676 & $295,471,559,739$ & - & - & + & - & - \\
\hline
\end{tabular}


Table 1. Cont.

\begin{tabular}{|c|c|c|c|c|c|c|c|c|c|c|}
\hline $\mathrm{Nr}$ & Rt (min) & Identified Compound & Compound Class & $\begin{array}{l}{[\mathrm{M}-\mathrm{H}], \mathrm{m} / \mathrm{z}} \\
\text { ESI Neg. }\end{array}$ & $\begin{array}{l}\text { Major MS-MS } \\
\text { Fragments }\end{array}$ & Pumpkin & Cucumber & Zucchini & $\begin{array}{l}\text { White } \\
\text { Pattypan } \\
\text { Squash }\end{array}$ & $\begin{array}{c}\text { Yellow } \\
\text { Pattypan } \\
\text { Squash }\end{array}$ \\
\hline 21 & 9.68 & octadecadienoic acid derivative & fatty acid & 413.217479 & $209,371,413$ & - & - & + & - & - \\
\hline 22 & 10.66 & $\begin{array}{l}\text { quercetin } 3,3^{\prime} \text {-dimethyl ether } \\
\text { 7-rutinoside }\end{array}$ & flavonoid & 637.176449 & $299,313,329,637$ & - & - & + & - & - \\
\hline 23 & 13.04 & octadecadienoic acid derivative & fatty acid & 327.218013 & 211,327 & + & - & + & + & + \\
\hline 24 & 14.17 & octadecadienoic acid derivative & fatty acid & 329.233674 & 211,329 & - & + & + & + & + \\
\hline 25 & 20.68 & glycerophospholipid & lipid & 636.316333 & $277,474,636$ & - & + & + & + & + \\
\hline 26 & 21.19 & glycerophospholipid & lipid & 636.315949 & $277,474,636$ & + & + & + & + & + \\
\hline 27 & 21.26 & glycerophospholipid & lipid & 562.315676 & $277,505,562$ & + & + & + & + & + \\
\hline 28 & 21.57 & $\gamma$-linolenic acid derivative & fatty acid & 721.364358 & $277,397,721$ & - & - & + & - & + \\
\hline 29 & 22.54 & glycerophospholipid & lipid & 638.331427 & $152,279,476,638$ & + & + & + & + & + \\
\hline 30 & 22.63 & glycerophospholipid & lipid & 564.331348 & $279,504,564$ & + & + & + & + & + \\
\hline 31 & 23.03 & $\gamma$-linolenic acid derivative & fatty acid & 559.311446 & 277,559 & - & - & + & - & - \\
\hline 32 & 23.06 & linoleic acid derivative & fatty acid & 564.329757 & $279,504,564$ & + & + & + & + & + \\
\hline 33 & 23.27 & glycerophospholipid & lipid & 614.330267 & $255,452,614$ & + & + & + & + & + \\
\hline 34 & 23.82 & glycerophospholipid & lipid & 452.277974 & 255,452 & - & - & + & + & + \\
\hline 35 & 23.89 & glycerophospholipid & lipid & 540.330582 & $255,480,540$ & + & + & + & + & + \\
\hline 36 & 24.46 & glycerophospholipid & lipid & 566.346313 & $281,506,566$ & + & + & - & + & + \\
\hline
\end{tabular}



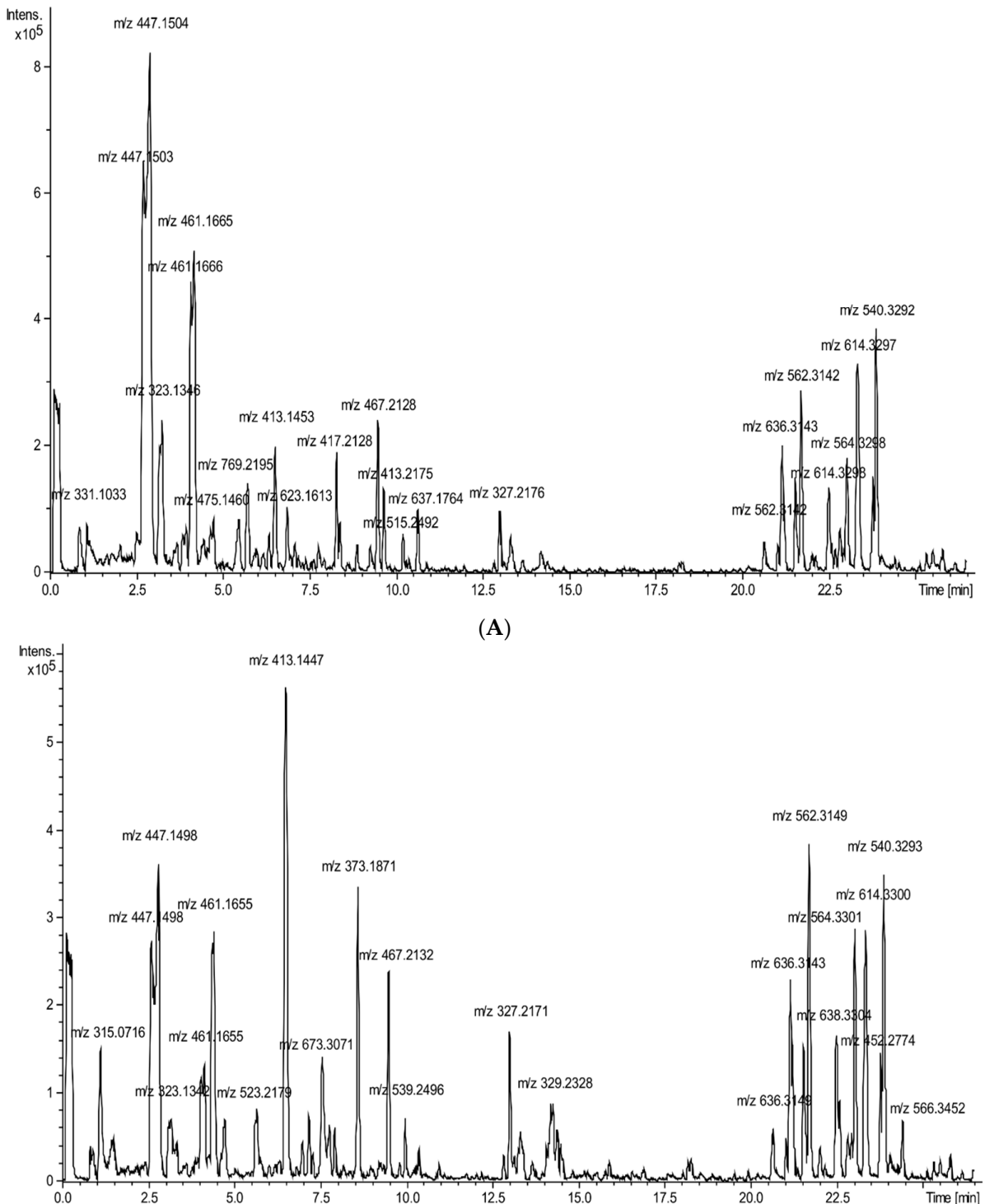

(B)

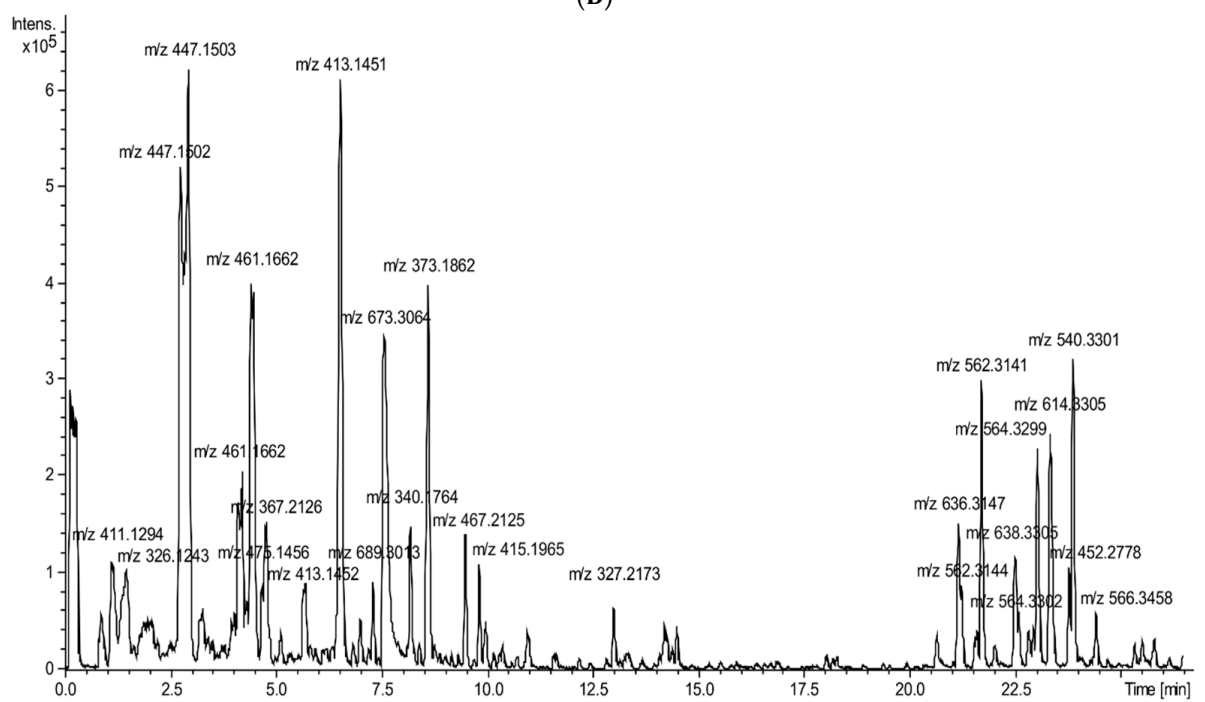

(C)

Figure 1. Cont. 


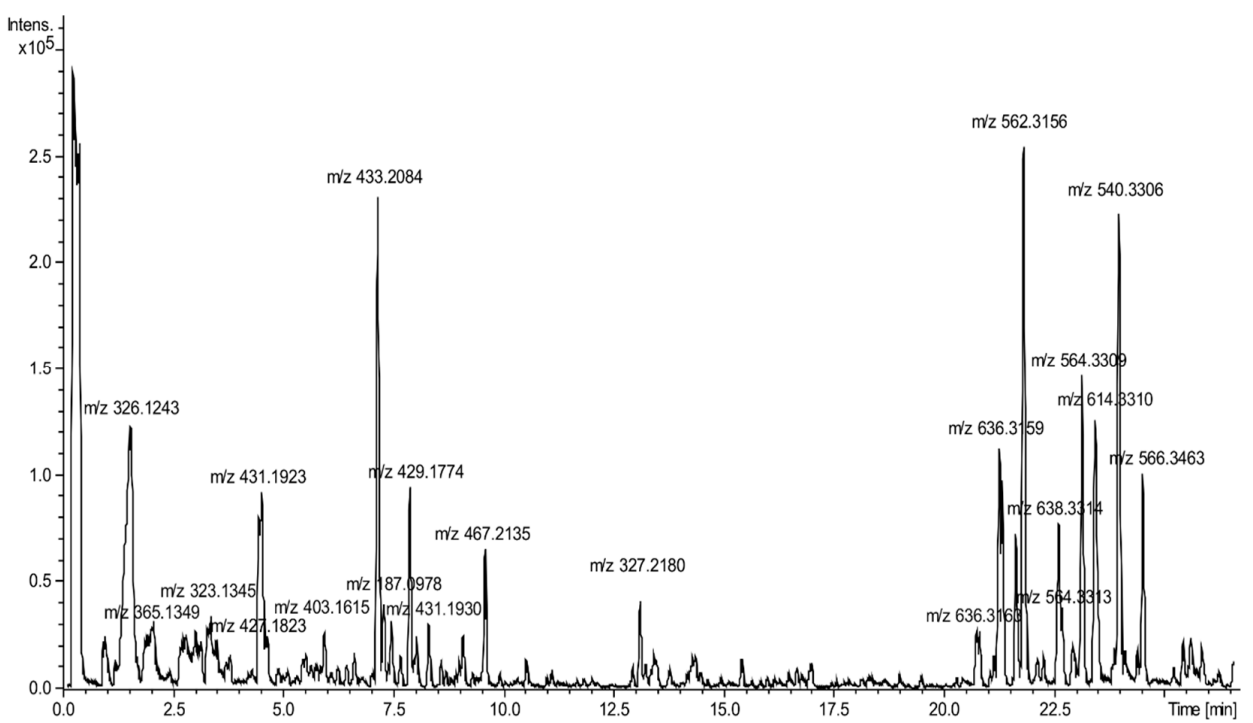

(D)

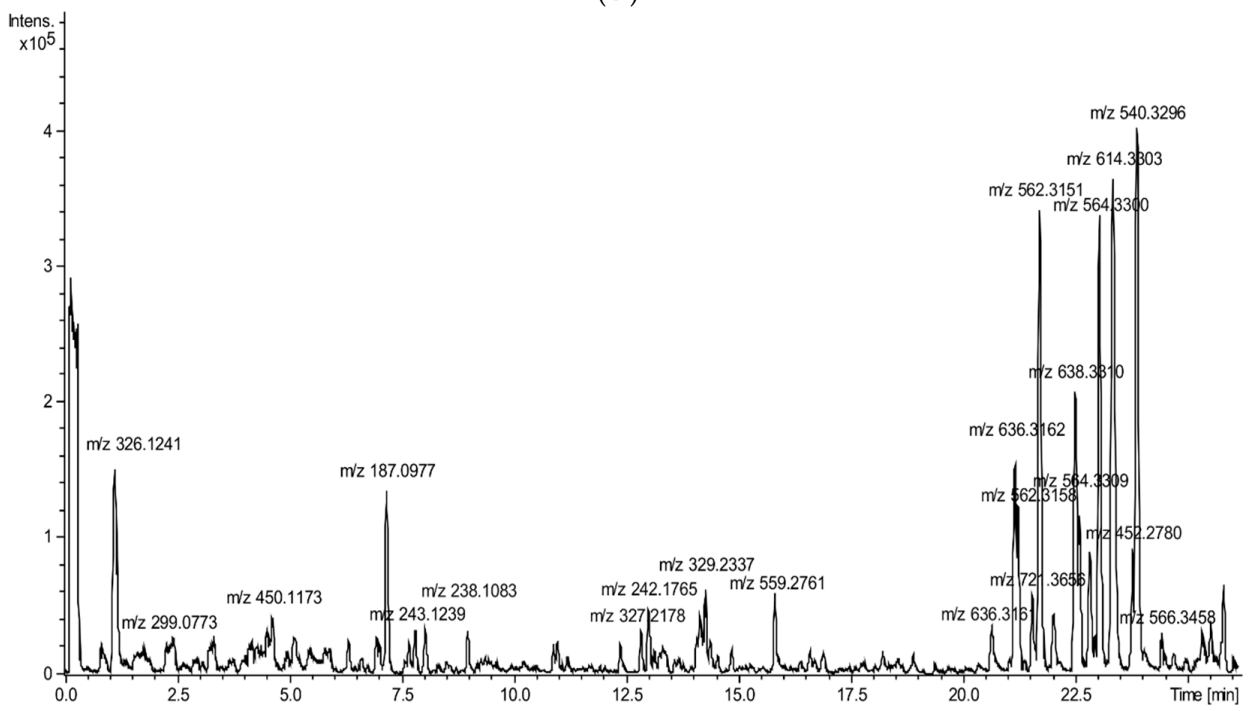

(E)

Figure 1. The base-peak chromatogram (BPC) of the five cucurbit vegetable preparations, obtained using high resolution UHPLC-ESI-QTOF-MS in negative ionization mode: preparation from zucchini (A), preparation from yellow pattypan squash (B), preparation from white pattypan squash (C), preparation from pumpkin (D), and preparation from cucumber (E).

\subsection{Effects of Vegetable Preparations on Hemostatic Parameters of Human Plasma}

The analysis of the effect on the coagulation properties of human plasma demonstrated that none of the tested cucurbit vegetable preparations (concentration range 1-50 $\mu \mathrm{g} / \mathrm{mL}$; incubation time $30 \mathrm{~min}$ ) changed APTT, PT or TT compared with control (plasma without cucurbits vegetables preparations $(p>0.05)$.

\subsection{Effects of Vegetable Preparations on Oxidative Stress Parameters}

The effect of the five cucurbit vegetable preparations (concentration range $1-50 \mu \mathrm{g} / \mathrm{mL}$; incubation time $30 \mathrm{~min}$ ) on the level of the three biomarkers of oxidative stress in human plasma was studied in vitro. We observed that the tested vegetable preparations did not exert any significant effect on oxidative stress in human plasma not treated with $\mathrm{H}_{2} \mathrm{O}_{2} / \mathrm{Fe}$ (data not demonstrated). On the other hand, exposure of plasma to $\mathrm{H}_{2} \mathrm{O}_{2} / \mathrm{Fe}$ (a strong oxidant) resulted in significant protein carbonylation, oxidation of thiol groups, and enhanced levels of lipid peroxidation (Figure 2A-C). As demonstrated in Figure 2A, 
only four vegetable preparations (pumpkin, cucumber, white pattypan squash and yellow pattypan squash at the highest concentration of $50 \mu \mathrm{g} / \mathrm{mL}$ ) reduced plasma protein carbonylation induced by $\mathrm{H}_{2} \mathrm{O}_{2} / \mathrm{Fe}$. The best result was obtained for the pumpkin preparation (reduction of this process by more than $60 \%$ in comparison to the control positive) (Figure 2A). As shown in Figure 2B, the tested vegetable preparations had different effects on the oxidation of the protein thiols in plasma treated with $\mathrm{H}_{2} \mathrm{O}_{2} / \mathrm{Fe}$. No positive effect was observed for two of the tested preparations (zucchini and white pattypan squash). On the other hand, for the yellow pattypan squash preparation, only at the highest dose $(50 \mu \mathrm{g} / \mathrm{mL})$ was it able to protect plasma against $\mathrm{H}_{2} \mathrm{O}_{2} / \mathrm{Fe}$-induced oxidation of protein thiols. The preparation from cucumber exerted the strongest effect at lower doses ( 1 and $5 \mu \mathrm{g} / \mathrm{mL}$ ) (Figure $2 \mathrm{~B}$ ). The best result was obtained for the pumpkin preparation at the concentration of $5 \mu \mathrm{g} / \mathrm{mL}$ (Figure $2 \mathrm{~B}$ ). Additionally, the activity of all tested vegetable preparations was not concentration-dependent for the $30 \mathrm{~min}$ incubation time (Figure 2B). Moreover, four of the tested preparations (zucchini, cucumber, white pattypan squash, and yellow pattypan squash) significantly $(p<0.05)$ inhibited plasma lipid peroxidation induced by $\mathrm{H}_{2} \mathrm{O}_{2} / \mathrm{Fe}$ starting from a dose of $1 \mu \mathrm{g} / \mathrm{mL}$ (Figure $2 \mathrm{C}$ ). The pumpkin preparation showed the highest activity at higher tested concentrations $(5$ and $50 \mu \mathrm{g} / \mathrm{mL})(p<0.05)$ (Figure 2C). However, the cucurbits preparations at both concentrations ( 5 and $50 \mu \mathrm{g} / \mathrm{mL}$ ) had non-significant influence on the antioxidant capacity of the ORAC plasma measures or, in concentration $50 \mu \mathrm{g} / \mathrm{mL}$, the total antioxidant capacity in vitro (Figure $3 \mathrm{~A}, \mathrm{~B}$ ).

The antiradical capacities of the five vegetable preparations are also shown in Figure 3C. The order of the DPPH scavenging activity for the preparations was as follows: cucumber $(0.007 \pm 0.00)<$ pumpkin $(0.052 \pm 0.00)<$ white pattypan squash $(0.064 \pm 0.01)<$ yellow pattypan squash $(0.086 \pm 0.01)<$ zucchini $(0.093 \pm 0.02)$ (Figure 3C).

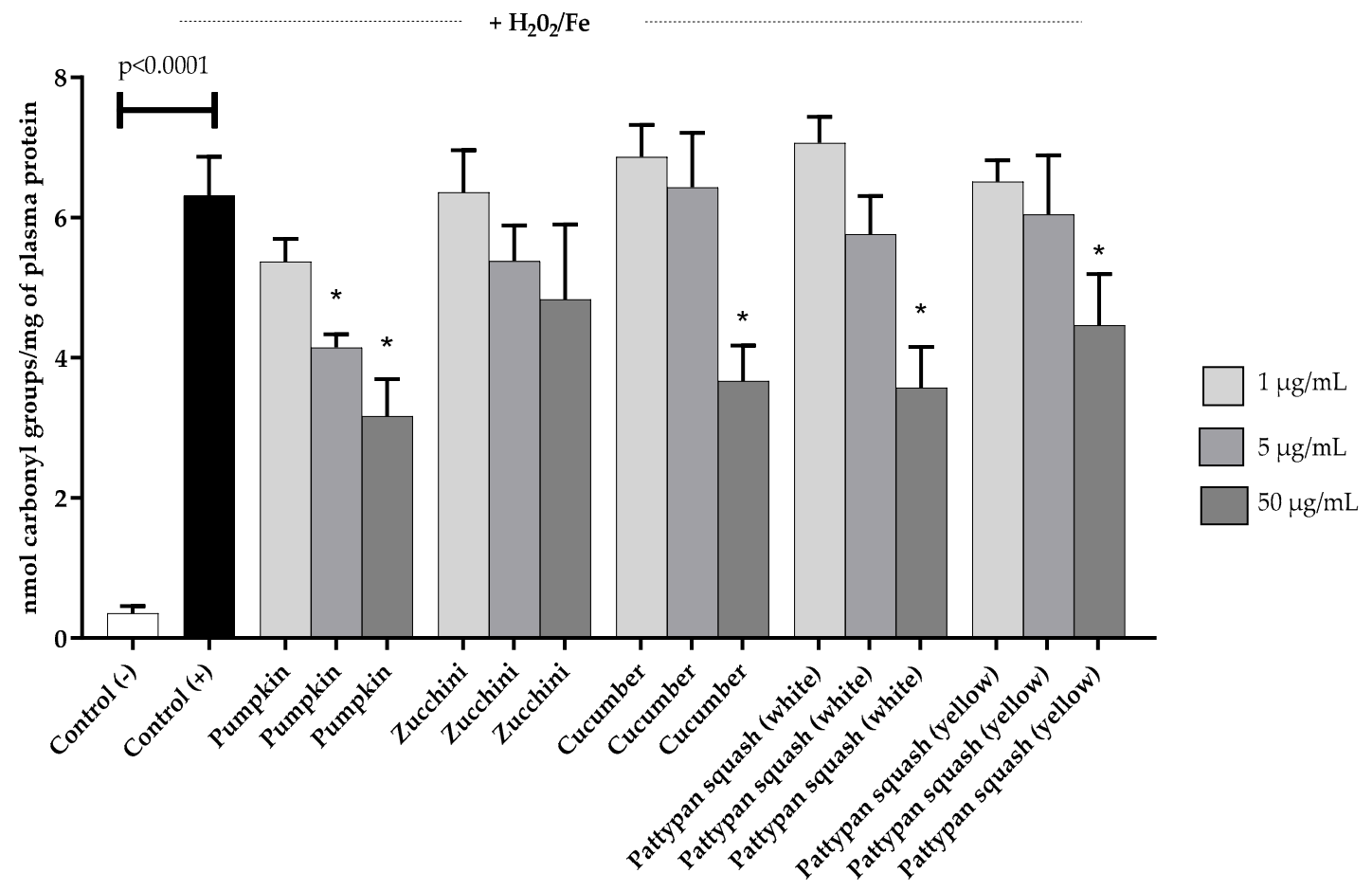

(A)

Figure 2. Cont. 


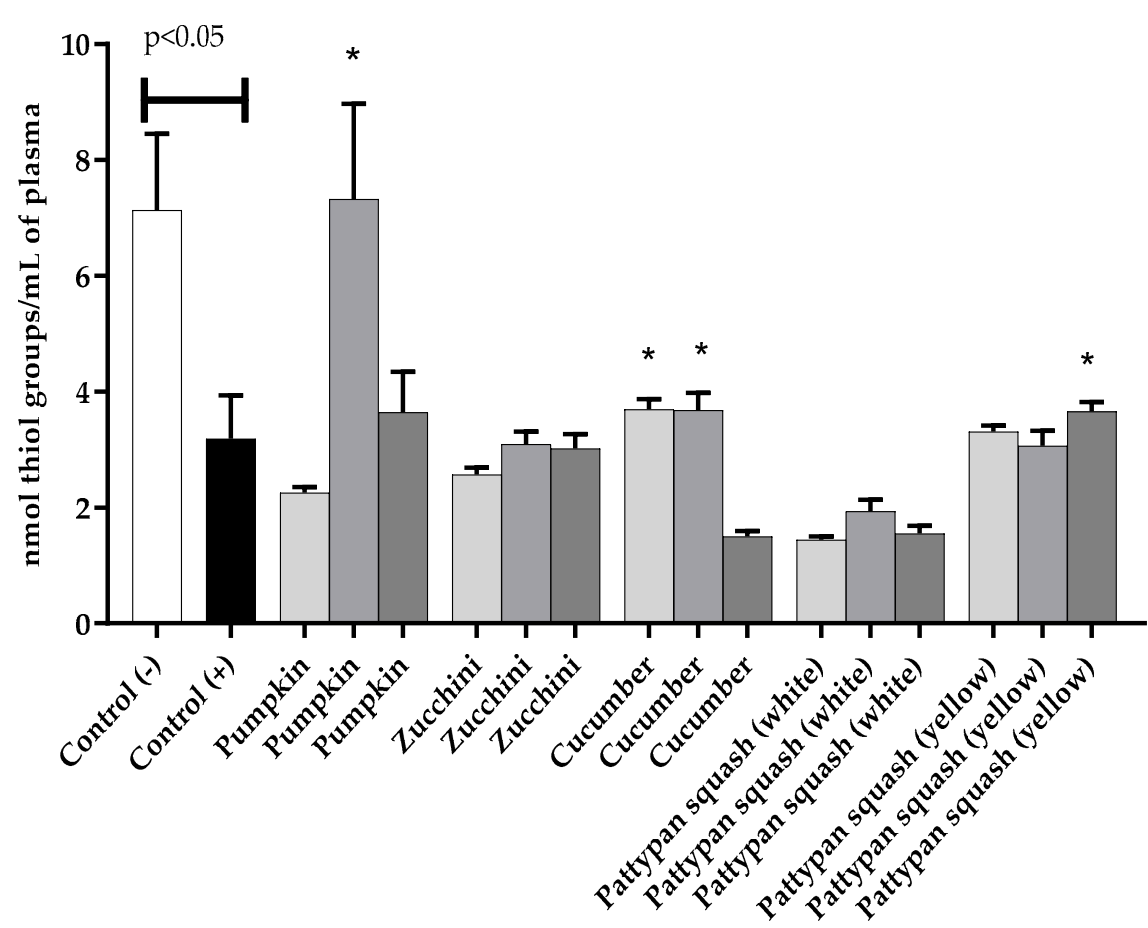

$1 \mu \mathrm{g} / \mathrm{mL}$

$5 \mu \mathrm{g} / \mathrm{mL}$

$50 \mu \mathrm{g} / \mathrm{mL}$

(B)

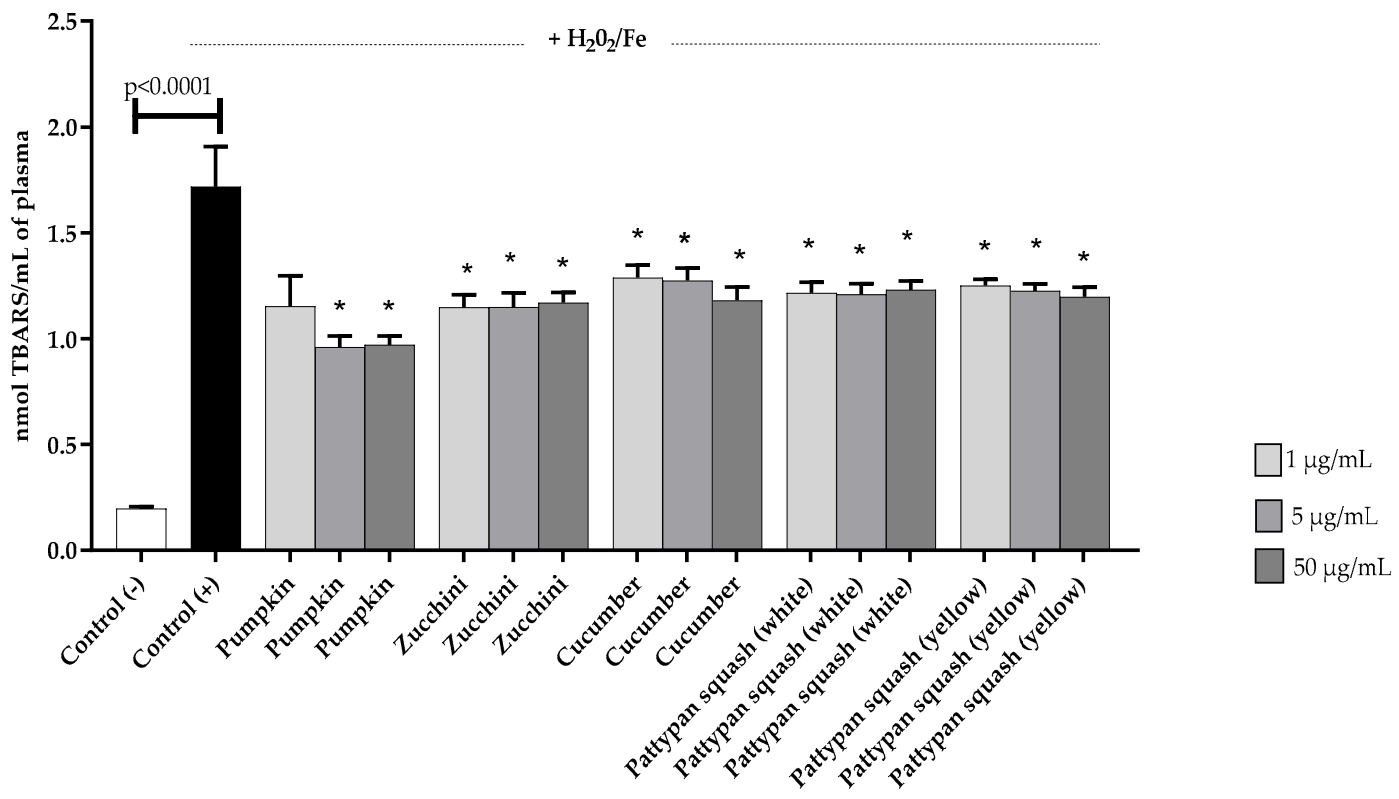

(C)

Figure 2. Effects of the five cucurbit vegetable preparations (concentration range 1-50 $\mathrm{mg} / \mathrm{mL}$, pre-incubation time $5 \mathrm{~min}$ ) on the oxidative damages of plasma protein-protein carbonylation, in plasma treated with $\mathrm{H}_{2} \mathrm{O}_{2} / \mathrm{Fe}$ (incubation time-25 $\mathrm{min}$ ) (A); on the oxidative damages of plasma proteins, the level of thiol groups in plasma treated with $\mathrm{H}_{2} \mathrm{O}_{2} / \mathrm{Fe}$ (incubation time $25 \mathrm{~min}$ ) (B); and on lipid peroxidation in plasma treated with $\mathrm{H}_{2} \mathrm{O}_{2} / \mathrm{Fe}$ (incubation time $25 \mathrm{~min}$ ) (C). Results are given as mean $\pm \mathrm{SE}(n=6)$. Control negative refers to plasma not treated with $\mathrm{H}_{2} \mathrm{O}_{2} / \mathrm{Fe}$, whereas control positive to plasma treated with $\mathrm{H}_{2} \mathrm{O}_{2} / \mathrm{Fe}$. One-way ANOVA followed by a multicomparison Tukey test and Kruskal-Wallis test: ${ }^{*} p<0.05$, compared with positive control (treated with $\mathrm{H}_{2} \mathrm{O}_{2} / \mathrm{Fe}$ ). 
Table 2 demonstrates the comparative effects of the five tested vegetable preparations (at the highest used concentration $50 \mu \mathrm{g} / \mathrm{mL}$ ) on selected biomarkers of oxidative stress in human plasma treated with $\mathrm{H}_{2} \mathrm{O}_{2} / \mathrm{Fe}$. Table 2 gives a full picture of comparison between the effect of all selected vegetables on different biomarkers of oxidative stress in human plasma. We observed that the yellow pattypan squash preparation had a stronger antioxidant potential than the other four preparations. The yellow pattypan squash preparation inhibited oxidative stress induced by $\mathrm{H}_{2} \mathrm{O}_{2} / \mathrm{Fe}$ in all the in vitro tests (Table 2).

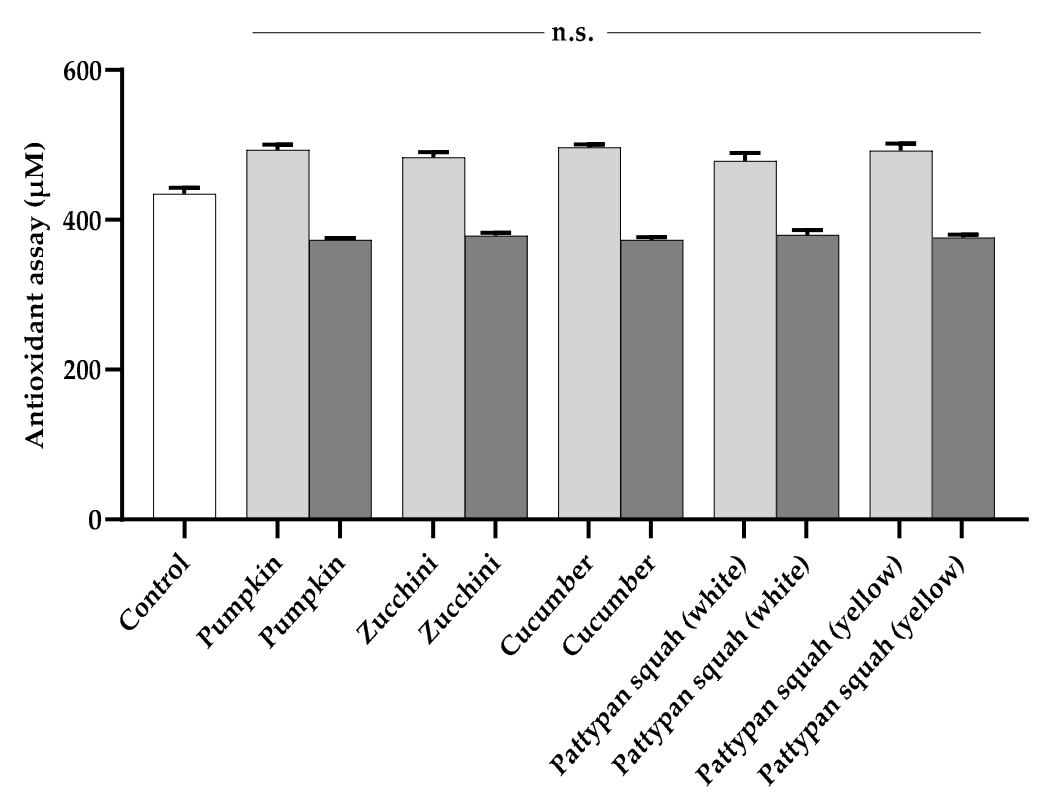

(A)

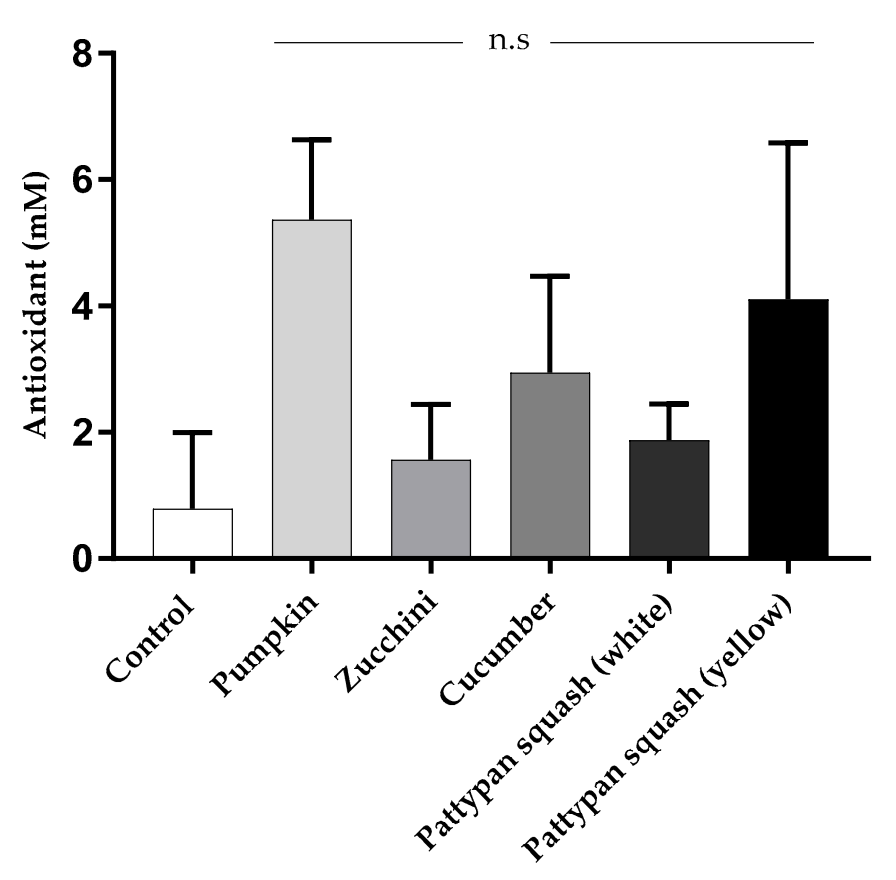

(B)

Figure 3. Cont. 


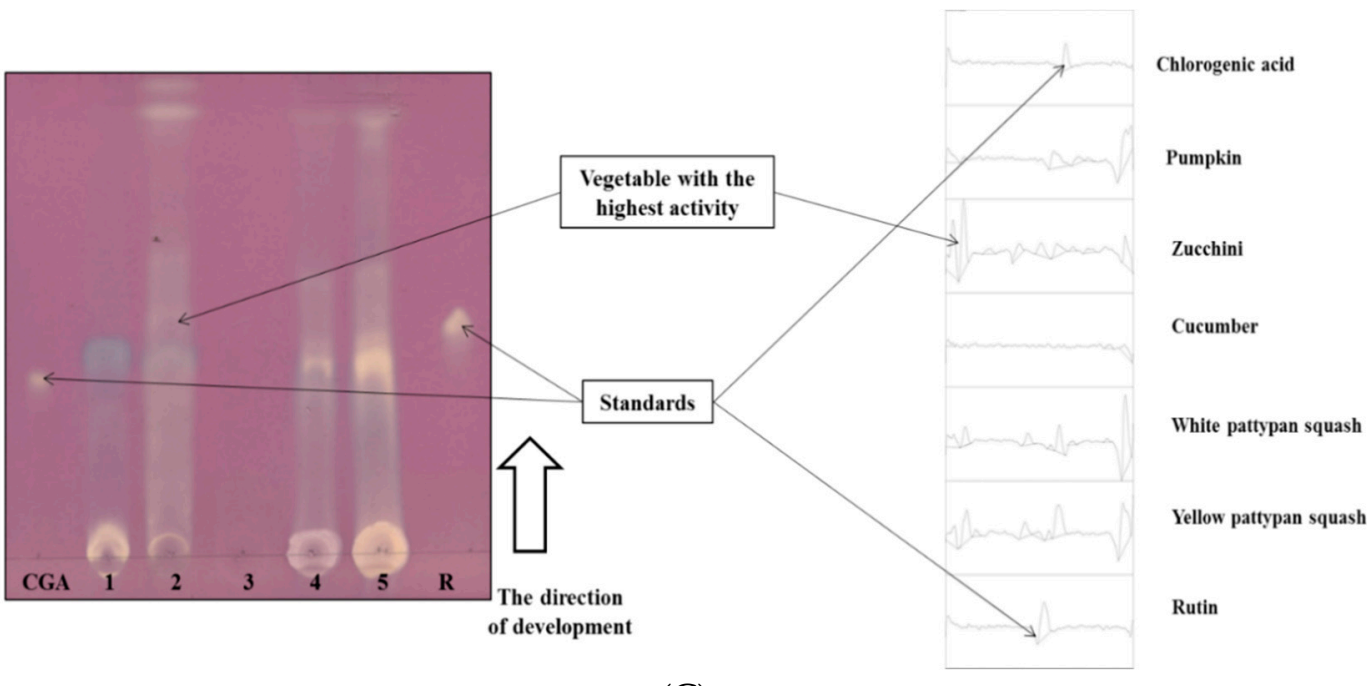

(C)

Figure 3. Effects of the five cucurbit vegetable preparations (incubation time $30 \mathrm{~min}$ ) on the plasma antioxidant capacity, measured as ORAC (oxygen radical antioxidant capacity) (A); on total antioxidant capacity of plasma $(\mathbf{B})$. Results are given as mean \pm SE $(n=5)$. One-way ANOVA followed by a multicomparison Tukey test and Kruskal-Wallis test, compared with control. The use of TLC-DPPH• assay for the detection of antioxidant activity of preparations from: 1-pumpkin, 2-zucchini, 3-cucumber, 4-white pattypan squash, 5-yellow pattypan squash. Standards: chlorogenic acid (CGA) and rutin (R) (C).

Table 2. Comparative effects of the five cucurbit vegetable preparations on oxidative stress in plasma treated with $\mathrm{H}_{2} \mathrm{O}_{2} / \mathrm{Fe}$ (tested concentration $50 \mu \mathrm{g} / \mathrm{mL}$ ).

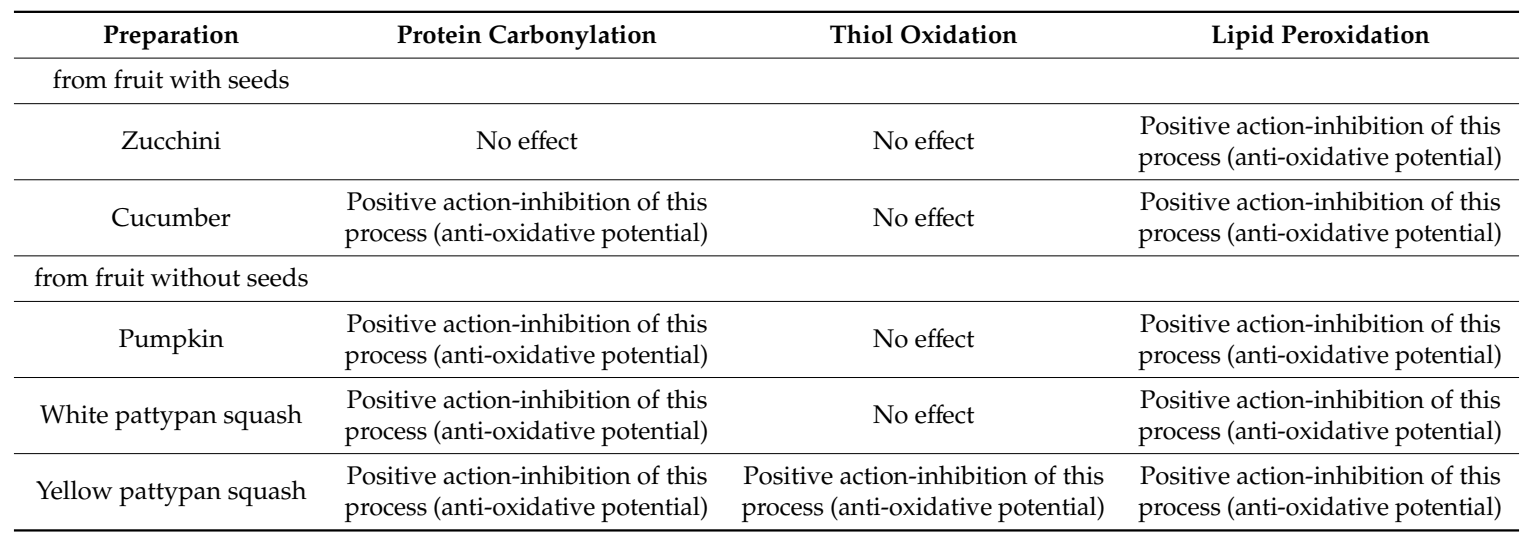

\section{Discussion}

Preparations from fruits and vegetables constitute a basis for modern phototherapy, as they contain concentrated active components, including phenolic compounds. The antioxidant or prooxidant properties of selected vegetables from the Cucurbitaceae family were studied in an in vitro model of human plasma exposed to oxidative stress. The stress conditions were induced by $\mathrm{H}_{2} \mathrm{O}_{2} / \mathrm{Fe}$, the donor of hydroxyl radicals (one of the strongest oxidative agents) involved in the pathophysiology of various processes. Hydroxyl radicals may interact with plasma lipids and proteins. The destructive effect of $\mathrm{OH}$ is reflected in the increased plasma levels of oxidative stress parameters such as TBARS, oxidation of thiol groups and protein carbonylation. The levels of these biomarkers have been connected with the progress or poorer prognosis of various diseases, for example cardiovascular diseases [16]. In our in vitro experiments, all tested preparations exerted a protective action in plasma proteins and lipids against hydroxyl radicals. Therefore, our present studies indicate that the tested vegetables from the 
Cucurbitaceae family may be promising candidates for the prevention and treatment of CVDs associated with oxidative stress.

The complex chemical composition of the preparations are likely related to their ability to modulate oxidative stress, and hence reduce the risk of cardiovascular diseases. On the other hand, the preparations neither failed to induce the total antioxidant capacity of plasma nor led to higher values of ORAC. However, in the DPPH free radical scavenging activity test, all five of the preparations differed in chemical composition and demonstrated antiradical properties. The zucchini preparation showed the highest radical scavenging effect of the preparations, because its phytochemical profile was the richest in terms of the presence of flavonoid compounds (Table 1). In general, the antioxidant activity of flavonoids depends on the structure and substitution pattern of the hydroxyl groups. The essential requirement for effective radical scavenging is the 4-carbonyl group in ring $\mathrm{C}$ and $3^{\prime}, 4^{\prime}$-orthodihydroxy configuration in ring $\mathrm{B}$. The presence of the 3-OH group or 3- and 5-OH groups, giving a catechol-like structure in ring $\mathrm{C}$, is also beneficial for the antioxidant activity of flavonoids. The presence of the C2-C3 double bond configured with a 4-keto arrangement is known to be responsible for electron delocalization from ring $\mathrm{B}$ and increases the radical-scavenging activity. In the absence of the o-dihydroxy structure in ring B, a catechol structure in ring A can compensate for flavonoid antioxidant activity. Quercetin has a catechol structure in ring B, as well as a 2,3-double bond in conjunction with a 4-carbonyl group in ring $C$, allowing the delocalization of the phenoxyl radical electron to the flavonoid nucleus. The combined presence of a 3-hydroxy group with a 2,3-double bond additionally increases the resonance stabilization for electron delocalization; hence, it has a higher antioxidant value. Flavonols (e.g., quercetin, isorhamnetin) have a hydroxyl group at position 3. Kim and Lee [17] suggest a structurally important role of the 3-OH group in the chroman ring responsible for the enhancement of antioxidant activity. The antioxidant activity of the zucchini preparation is a result of rutin, isorhamnetin 3-O-rutinoside, hesperetin 7-O- $\left(2^{\prime \prime}, 6^{\prime \prime}\right.$-di-O- $\alpha$-rhamnopyranosyl)- $\beta$-glucopyranoside, xanthorhamnin and quercetin 3,3'-dimethyl ether 7-rutinoside contents. The results of Iswaldi et al. [14] showed that sixteen flavonoids and other polar compounds with their derivatives were identified in the whole zucchini vegetables. The yellow pattypan squash preparation also showed a high antioxidant activity, which was significantly influenced by the very high content of benzoic acid derivatives, mainly 3-( $\beta$-D-glucopyranosyloxy)-2-hydroxybenzoic acid [14].

The results of the inorganic experimental system (DPPH test) did not quite coincide with those obtained in the biological experimental system (human plasma treated with a strong physiological inducer of oxidative stress, $\mathrm{H}_{2} \mathrm{O}_{2} / \mathrm{Fe}$ ). However, the tested preparations showed antioxidant activities of different levels in vitro. In this biological system, in vitro, the yellow pattypan squash preparation had the strongest antioxidant properties, and inhibited oxidative stress induced by $\mathrm{H}_{2} \mathrm{O}_{2} / \mathrm{Fe}$ in all the tests: plasma lipid peroxidation, oxidation of thiol groups in plasma proteins and plasma protein carbonylation. In addition, it seems to be important that the preparations often demonstrated antioxidant activity even at low concentrations: 1 and $5 \mu \mathrm{g} / \mathrm{mL}$. The best antioxidant activity of yellow pattypan squash may be due to the presence of a benzoic acid derivative level. The antioxidant activity of benzoic acid derivatives correlates with the presence of the phenolic group and the position of the hydroxyl group. Velika and Kron [18] discovered that derivatives with a blocked hydroxyl group showed lower antioxidant properties than derivatives with a blocked carbonyl group. The pattypan squash yellow preparation, in comparison to the other preparations, contain phenylpropanoids glycoside, which could be another reason for its antioxidant activity in plasma. Phenylpropanoid glycoside showed a strong antioxidant activity, such as inhibition of oxidation of low-density lipoprotein through free radical scavenging and metal ion chelation, which correlates with the presence of the phenylpropanoid and phenylethanoid groups in the structure. Thuan et al. [19] demonstrated that phenylpropanoid glycoside isolated from Picria tel-ferae can inhibit lipid peroxidation in an in vitro model using TBARS assay $[19,20]$.

The pumpkin preparation inhibited protein carbonylation and lipid peroxidation in the plasma in the in vitro model. The pumpkin preparation was the only one to have a high content of phenolic 
acid, which lead to the display of antioxidant properties. Xanthopoulou et al. [21] proved a correlation between phenolic compound content and the antioxidant activity of pumpkin. The antioxidant activities of pumpkin seed extracts were determined using a DPPH free radical assay. The results showed that pumpkin seed extract demonstrated a phenol concentration-dependent antiradical activity [21]. The cucumber and white pattypan squash preparations showed similar effects to the pumpkin. Both preparations inhibited protein carbonylation and lipid peroxidation in plasma. The zucchini preparation only inhibited lipid peroxidation in plasma. Zucchini contain the highest level of flavonoids of all the tested preparations. Khennouf et al. [22] reported that flavonoids have a strong free radical scavenging ability and can inhibit xanthine oxidase activity, a source of oxygen free radicals. Flavonoids also inhibit lipids, but at a lower level than other secondary plant metabolites, such as tannins and phenolic compounds [22]. Other researchers also observed that preparations from vegetables of the Cucurbitaceae family may reduce oxidative stress in vitro, and in the in vivo models. For example, Cucurbita maxima pumpkin pectin inhibited oxidative stress induced by 2,2'-azobis(2-methylpropionamide) dihydrochloride in cell cultures (cell lines HT-29, human colon adenocarcinoma), and MDCK1 (canine kidney epithelium). Oxidative stress was measured by the production of intracellular reactive species [23]. In another in vitro model, Shayesteh et al. [24] also demonstrated the protective effects of pumpkin fruit extract against oxidative stress. Cumene hydroperoxide and glyoxal were used as inductors of oxidative stress in freshly isolated rat hepatocytes. The tested extract $(50 \mu \mathrm{g} / \mathrm{mL})$ reduced oxidative stress as measured by various parameters, including lipid peroxidation, reactive oxygen species production and glutathione depletion. The same activity was observed by Bahramsoltani et al. [25]. Moreover, the results of Abarikwu et al. [26] demonstrated that fluted pumpkin seeds $(200 \mathrm{mg} / \mathrm{kg}$ body wt.) protect against busulfon-induced oxidative stress in adult mice. The effect of ethanolic extract of fluted pumpkin seeds was investigated after 40 days of oral administration. Ghahremanloo et al. [27] have also observed that pumpkin extract ameliorates oxidative stress in obese rats, leading to decreased cardiovascular disease risk in obesity. Three groups of obese rats received hydroalcoholic extract of pumpkin as one daily dose of 100,200 and $400 \mathrm{mg} / \mathrm{kg}$, respectively. At the end of six weeks, the parameters of oxidative stress were measured [27].

Oxidative stress may alter the coagulation process, and this may lead to the development of CVDs [16]. However, it is not known whether the tested preparations are associated with the modulation coagulation process, or whether they have an antithrombotic activity. For the first time, in our present study on these five preparations, we found that they did not change the coagulation system, and did not show anticoagulant or procoagulant potential in the in vitro model. Therefore, we suggest that the preparations may be a source of antioxidants that do not incur the risk of bleeding or thrombosis [16].

\section{Materials and Methods}

\subsection{Chemicals}

Methanol and acetonitrile, HPLC grade, were purchased from Merck (Darmstadt, Germany). Formic acid, LC-MS grade, was purchased from Sigma-Aldrich, (St. Louis, MO, USA). Ultrapure water was obtained in-house with a purification system (Milli-Q-Simplicity-185, Millipore Corp.). Dimethylsulfoxide (DMSO), thiobarbituric acid (TBA) and $\mathrm{H}_{2} \mathrm{O}_{2}$ were purchased from Sigma (St. Louis, $\mathrm{MO}$, USA). Other reagents were of analytical grade and were provided by commercial suppliers, including POCh, (Poland), Acros (Poland) and Chempur (Poland).

\subsection{Plant Material}

Five cucurbit vegetable types were selected, and subjected to freeze-drying (CHRIST Gamma 2-16 LSC Freeze Dryers, Osterode am Harz, Germany): pumpkin (Cucurbita pepo L., fruit without seeds); zucchini (Cucurbita pepo L. convar. Giromontina, fruit with seeds); cucumber (Cucumis sativus L., fruit with seeds); white pattypan squash (Cucurbita pepo L. var. patisoniana, fruit without seeds) and 
yellow pattypan squash (Cucurbita pepo L. var. patisoniana, fruit without seeds). The plant material was stored at the Department of Biochemistry and Crop Quality of the Institute in Puławy, Poland.

\subsection{Extraction and Preparation of Vegetable Preparations}

Plant materials ( $1 \mathrm{mg}$ of each of the freeze-dried vegetables) were extracted using an automatic extractor, Dionex ASE 200 Accelerated Solvent Extraction System. The extraction process conditions were as follows: extraction solvent: $80 \%$ methanol, solvent pressure: 1500 psi, extraction cell temperature: $40^{\circ} \mathrm{C}$, extraction cycles: 3 . The extracts were evaporation dried under reduced pressure, at $40{ }^{\circ} \mathrm{C}$ (Heidolph Hei-Vap Advantage, rotary evaporator). The five extracts were purified, mainly from sugars, by solid phase extraction (SPE). Specialized metabolite fractions were eluted from Oasis Extraction Cartridges (Waters, MA, USA) with $6 \mathrm{~mL}$ of $85 \%$ methanol. The evaporated eluate was dissolved in $70 \% \mathrm{MeOH}$. Next, the samples were cleaned in an ultrasonic bath for $5 \mathrm{~min}$ at $30^{\circ} \mathrm{C}$ (SONOREX DIGITEC DT $510 \mathrm{H}$, Bandelin, Germany) and centrifuged for $5 \mathrm{~min}$ at $10,000 \mathrm{rpm}$ at $20^{\circ} \mathrm{C}$ (laboratory centrifuge: Polygen Sigma 3-16 KL, Sigma, Germany). Finally, $150 \mu \mathrm{L}$ of the supernatant from each sample was subjected to HPLC-MS analysis.

\subsection{Phytochemical Profiling}

The quantitative analysis of each preparation was carried out by ultra-high resolution mass spectrometry (UHRMS) using a Dionex UltiMate 3000RS (Thermo Scientific, Darmstadt, Germany) system with a charged aerosol detector (CAD) interfaced with a high-resolution quadrupole time-of-flight mass spectrometer (HR/Q-TOF/MS, Impact II, Bruker Daltonik GmbH, Bremen, Germany). The chromatographic separation was performed on an Acquity UPLC BEH C18 column $(100 \times 2.1 \mathrm{~mm}$, $1.7 \mu \mathrm{m}$, Waters, Manchester, UK), with the column temperature maintained at $60^{\circ} \mathrm{C}$. The mobile phases were acidified ( $0.1 \%$ formic acid) water (solvent $\mathrm{A}$ ) and acidified ( $0.1 \%$ formic acid) acetonitrile (solvent B). The chromatographic method consisted of the following linear gradient: $7 \% \mathrm{~B}$ from 0 to $0.5 \mathrm{~min}$ and then the concentration of B was increased to $80 \%$ from 0.5 to $26 \mathrm{~min}$. The sample injection volume was $1.0 \mu \mathrm{L}$ and the flow rate was set at $500 \mu \mathrm{L} / \mathrm{min}$. Compounds were analyzed based on data from the mass spectra. Electrospray ionization (ESI) was performed in negative ion mode. The mass scan range was set at $50-2000 \mathrm{~m} / \mathrm{z}$. Ion source parameters were as follows: capillary voltage $3.0 \mathrm{kV}$, collision energy $20.0 \mathrm{eV}$, dry gas $6.0 \mathrm{~L} / \mathrm{min}$ and dry temperature $200^{\circ} \mathrm{C}$. Data acquisition and processing were performed using DataAnalysis 4.3 (Bruker Daltonik GmbH, Bremen, Germany). Determination of molecular formula was carried out by mass accuracy, adduct, and fragment information using SmartFormula.

\subsection{Stock Solutions of Vegetable Preparation}

The stock solutions of vegetable preparations, used in the tests for biological activity, were made in $50 \%$ DMSO. The final concentration of DMSO in the samples (human plasma) was lower than $0.05 \%$ and its effects were determined in all experiments.

\subsection{Human Plasma Isolation}

Human blood or plasma were obtained from six regular donors (non-smoking men and women) to a blood bank (Lodz, Poland) and a medical center (Lodz, Poland). Blood was collected as a CPD solution (citrate/phosphate/dextrose; 9:1; v/v blood/CPD) or CPDA solution (citrate/phosphate/dextrose/adenine; 8.5:1; v/v; blood/CPDA). Donors had not taken any medication or addictive substances (including tobacco, alcohol and antioxidant supplementation) for at least two week before a donation. Our analysis of the blood samples was performed under the guidelines of the Helsinki Declaration for Human Research, and approved by the Committee on the Ethics of Research in Human Experimentation at the University of Lodz (resolution ref. 8/KBBN-UŁ/III/2018). The plasma was isolated by differential centrifuging as described earlier [28]. The plasma was incubated $\left(30 \mathrm{~min}\right.$, at $37^{\circ} \mathrm{C}$; for hemostatic parameters) with vegetable preparations at the final concentrations of $1-50 \mu \mathrm{g} / \mathrm{mL}$. Human plasma was also pre-incubated $\left(5 \mathrm{~min}\right.$, at $37^{\circ} \mathrm{C}$; for parameters of oxidative stress) with vegetable preparations 
at the final concentrations of 1-50 $\mu \mathrm{g} / \mathrm{mL}$, and then treated with $4.7 \mathrm{mM} \mathrm{H}_{2} \mathrm{O}_{2} / 3.8 \mathrm{mM} \mathrm{Fe}_{2} \mathrm{SO}_{4} / 2.5 \mathrm{mM}$ $\operatorname{EDTA}\left(25 \mathrm{~min}\right.$, at $\left.37^{\circ} \mathrm{C}\right)$.

The protein concentration, determined by measuring absorbance at $280 \mathrm{~nm}$ according to the procedure of Whitaker and Granum [29], was measured using Bradford protein assay [30].

\subsection{Markers of Oxidative Stress}

\subsubsection{Lipid Peroxidation Measurement}

Lipid peroxidation was quantified by measuring the concentration of TBARS, according to the method described by Wachowicz [31] and Bartosz [32]. After $30 \mathrm{~min}$ of incubation with a preparation from Cucurbitaceae vegetables at the final concentrations of $1-50 \mu \mathrm{g} / \mathrm{mL}$, the samples were mixed with an equal volume of cold $15 \%(v / v)$ trichloroacetic acid $\left(\mathrm{C}_{2} \mathrm{HCl}_{3} \mathrm{O}_{2}\right)$ in $0.25 \mathrm{M} \mathrm{HCl}$ and $0.37 \%(v / v)$ TBA in $0.25 \mathrm{M} \mathrm{HCl}$, and then immersed in a boiling water bath for $15 \mathrm{~min}$. After cooling, the absorbance was measured at $535 \mathrm{~nm}$ using the SPECTROstar Nano Microplate Reader (BMG LABTECH, Ortenberg, Germany). The TBARS concentration was calculated using the molar extinction coefficient $\left(\varepsilon=156,000 \mathrm{M}^{-1} \mathrm{~cm}^{-1}\right)$ and was expressed as $\mathrm{nmol} / \mathrm{mL}$ of plasma.

\subsubsection{Carbonyl Group Measurement}

The carbonyl groups were determined in plasma proteins according to Levine et al. [33] and Bartosz [32]. The absorbance measurement (at $\lambda=375 \mathrm{~nm}$ ) was performed using the SPECTROstar Nano Microplate Reader (BMG LABTECH, Ortenberg, Germany). The carbonyl group concentration was calculated using a molar extinction coefficient $\left(\varepsilon=22,000 \mathrm{M}^{-1} \mathrm{~cm}^{-1}\right)$ and was expressed as $\mathrm{nmol} / \mathrm{mg}$ of plasma protein.

\subsubsection{Thiol Group Measurement}

The thiol group content was measured spectrophotometrically (absorbance at $\lambda=412 \mathrm{~nm}$ ), using a SPECTROstar Nano Microplate Reader (BMG LABTECH, Ortenberg, Germany), with 5,5'-dithio-bis-(2-nitrobenzoic acid) (Ellman's reagent) according to the method described by Ando and Steiner [34,35] and Bartosz [32]. The thiol group concentration was calculated using a molar extinction coefficient $\left(\varepsilon=13,600 \mathrm{M}^{-1} \mathrm{~cm}^{-1}\right)$ and was expressed as $\mathrm{nmol} / \mathrm{mL}$ of plasma protein.

\subsubsection{TLC-DPPH• Test}

The free radical scavenging potential of the pumpkin, zucchini, cucumber, white and yellow pattypan squash preparations was assessed by means of a simple benchtop TLC-DPPH• bioassay with ImageJ program. This method, with small modifications, has been found suitable for the analysis of complex samples, as proved in our previous publications [36-38].

Preparations $(5 \mathrm{mg} / \mathrm{mL})$ and standard compounds, chlorogenic acid $((1 S, 3 R, 4 R, 5 R)-3-\{[(2 E)$ -3-(3,4-dihydroxyphenyl)prop-2-enoyl]oxy\}-1,4,5-trihydroxycyclohexanecarboxylic acid) and rutin (2-(3,4-dihydroxyphenyl)-5,7-dihydroxy-3-[ $\alpha$-L-rhamnopyranosyl-(1 $\rightarrow 6)-\beta$-D-glucopyranosyloxy]-4H -chromen-4-one), $1 \mathrm{mg} / \mathrm{mL}$, were prepared and applied to aluminum-backed silica gel (60 F254, Merck) chromatographic plates, with an $8 \mathrm{~mm}$ gap between them, and at $10 \mathrm{~mm}$ from both the left and low edges, using a micropipette with a scale. The plates were developed in vertical chambers pre-saturated for $15 \mathrm{~min}$ with the optimized mobile phase: acetonitrile:chloroform:water:formic acid (80:10:10:5, $v / v / v / v)$. The plates were developed at a distance of $90 \mathrm{~mm}$ and dried in a hood for $30 \mathrm{~min}$ before derivatization. Next, the TLC plates were immersed for $5 \mathrm{~s}$ in a freshly prepared $0.2 \%(w / v)$ methanolic $\mathrm{DPPH} \bullet$ solution. After removing the DPPH• excess, the plates were stored in the dark for $30 \mathrm{~min}$ and then scanned by means of a flatbed scanner. Compounds with the ability to scavenge free radicals emerged as a yellow band against a purple background. The test was performed in triplicate. 


\subsubsection{Image Processing Procedure}

The results of the TLC-DPPH• test were documented by flat-bed scanning, saved in the form of jpg image files and further processed by means of an open source and free program, ImageJ, developed at the National Institute of Health in the USA.

For the DPPH• staining, the results change over time, and therefore it is crucial to precisely define the time that elapses between immersion and documentation. The results were documented every 10 min for an hour, and after the comparison it was decided to process the images taken $30 \mathrm{~min}$ after staining. Subsequently the images chosen were processed by means of the ImageJ program, with the use of a modified procedure following Olech et al. [39]. In summary, the color images were converted to 8-bit type images (Image/Type/8-bit). These images were denoised by applying the following steps: Process/Filters/Median/Radius-20 pixels. The baseline drift was removed (Process/FFT/Bandpass Filter/Filter large structures down to-120 pixels; filter small structures up to-0 pixels). The images processed in this way were then inverted (Edit/Invert). In order to change the videoscan images into chromatograms, resembling those obtained in high-performance liquid chromatography (HPLC), a rectangular selection tool was used to outline the tracks. The line profile plots were obtained in the same way as described in the original procedure [39]. The areas under the common peaks were measured and compared with the area obtained for chlorogenic acid and rutin, a compound with a recognized free radical scavenging potential.

\subsubsection{ORAC Assay}

ORAC is based on a hydrogen atom transfer (HAT) process, with oxidation of a fluorescent probe by peroxyl radicals. The role of the antioxidant in the assay is to block peroxyl radical oxidation of the fluorescent probe until the whole antioxidant activity in the sample is complete. The sample antioxidant activity is associated with the fluorescence decay curve, which is represented as the area under the curve (AUC), used to measure total peroxyl radical antioxidant activity and compare to the antioxidant standard curve of Trolox, a water-soluble tocopherol analogue. The Trolox curve was prepared on the same plate as all samples and according to the instructions supplied in the kit. The procedure for the ORAC assay was performed on plasma according to the instructions supplied with the Oxygen Radical Antioxidant Capacity (ORAC) Assay kit from CELL BIOLABS, INC (San Diego, USA). The kit included a 96-well microtiter plate with clear bottom black plate, fluorescein probe 100×, free radical initiator, antioxidant standard (Trolox $\left.{ }^{\mathrm{TM}}\right)$, and assay diluent $(4 \times)$. The samples at concentration 5 and $50 \mu \mathrm{g} / \mathrm{mL}$ were dissolved in the ratio 1:100 [40].

\subsubsection{Total Antioxidant Capacity of Plasma}

Total antioxidant capacity of plasma (with a preparation from Cucurbitaceae) can be measured by the antioxidant ability of metmyoglobin to inhibit the oxidation of 2,2'-azino-di-[3-etyhylbenthiazoline sulphonated] (ATBS) in the sample. The amount of ABTS can be monitored by measuring the absorbance at $750 \mathrm{~nm}$. The antioxidant in the sample causes suppression of the absorbance to a degree proportional to its concentration. The antioxidant capacity of the sample is compared with that of Trolox, a water-soluble tocopherol analogue. The Trolox curve was prepared on the same plate as all samples and according to instructions supplied in kit. The procedure for total antioxidant capacity was performed on plasma according to the instructions supplied with the Antioxidant Assay KIT from Cayman Chemical (Ann Arbor, MI, USA). The kit included Antioxidant Assay Buffer (10x), Antioxidant Assay Chromogen, Antioxidant Assay Metmyoglobin, Antioxidant Assay Trolox, Antioxidant Assay Hydrogen Peroxide, and a 96-well solid plate. The samples at concentration $50 \mu \mathrm{g} / \mathrm{mL}$ were dissolved $1: 20[41]$. 


\subsection{Parameters of Coagulation}

\subsubsection{Measurement of Prothrombin Time (PT)}

The PT was determined coagulometrically using an Optic Coagulation Analyser, model K-3002 (Kselmed, Grudziadz, Poland), according to the method described by Malinowska et al. [42]. Briefly, after 30 min of treatment with a Cucurbitaceae preparation, the human plasma $(50 \mu \mathrm{L})$ was incubated for $2 \mathrm{~min}$ at $37^{\circ} \mathrm{C}$ and then, directly before measurement, $100 \mu \mathrm{L}$ of Dia-PT liquid (commercial preparation: Kselmed, Grudziadz, Poland) was added.

\subsubsection{Measurement of Thrombin Time (TT)}

The TT was determined coagulometrically using an Optic Coagulation Analyser, model K-3002 (Kselmed, Grudziadz, Poland), according to the method described by Malinowska et al. [42]. Briefly, after treatment with the Cucurbitaceae preparation, the human plasma $(50 \mu \mathrm{L})$ was incubated for $1 \mathrm{~min}$ at $37^{\circ} \mathrm{C}$ and then, directly before measurement, $100 \mu \mathrm{L}$ of thrombin was added (final concentration was $5 \mathrm{U} / \mathrm{mL}$ ).

\subsubsection{Measurement of Activated Partial Thromboplastin Time (APTT)}

The APTT was determined coagulometrically using an Optic Coagulation Analyser, model K-3002 (Kselmed, Grudziadz, Poland), according to the method described by Malinowska et al. [42]. Briefly, after treatment with the Cucurbitaceae preparation, the human plasma (50 $\mu \mathrm{L})$ was incubated with 50 $\mu \mathrm{L}$ of Dia-PTT liquid (commercial thromboplastin: Kselmed, Grudziadz, Poland) for 3 min at $37^{\circ} \mathrm{C}$ and then, directly before measurement, $50 \mu \mathrm{L}$ of $25 \mathrm{mM} \mathrm{CaCl} 2$ was added.

\subsection{Data Analysis}

Several tests were used to carry out the statistical analysis. All the values in this study were expressed as mean \pm SE. The results were first evaluated for normality with the Kołmogorowa-Smirnowa test and equality of variance with the Levine test. Statistically significant differences were assessed by applying the ANOVA test (significance level was $p<0.05$ ), followed by a Tukey multiple comparisons test or Kruskal-Wallis test.

\section{Conclusions}

The present paper is the first detailed study of these five preparations from selected vegetables from the Cucurbitaceae family and provides new insights into their phytochemical composition and biological activity (using human plasma). In this work, the UHPLC-ESI-QTOF-MS system was used to identify different compounds in the tested preparations. The results revealed that these preparations have various bioactive compounds with antioxidant activities for use in the prophylaxis and treatment of diseases involving oxidative stress, including CVDs. Although antioxidant properties were demonstrated in an in vitro model, the real effect of these extracts should be verified in an in vivo model.

Author Contributions: A.R., A.S. (Agata Soluch) and I.K. data curation, A.R., I.K., A.S. (Agata Soluch) and B.O.-writing original draft, A.R. and I.K. investigation B.O, A.S. (Anna Stochmal) and I.K. conceptualization, B.O., I.K. and A.S. (Anna Stochmal) project administration. All authors have read and agreed to the published version of the manuscript.

Funding: Publication's printing cost was co-financed by the European Union from the European Social Fund under the "InterDOC-STARt" project (POWR.03.02.00-00-I033/16-00).

Acknowledgments: The authors would like to thank Mariusz Kowalczyk (Department of Biochemistry and Crop Quality, Institute of Soil Science and Plant Cultivation, State Research Institute, Pulawy) for UPLCESI-QTOF-MS analysis. 
Conflicts of Interest: The authors declare no conflict of interest. The funders had no role in the design of the study; in the collection, analyses, or interpretation of data; in the writing of the manuscript, or in the decision to publish the results.

\section{References}

1. Olas, B. Anti-aggregatory potential of selected vegetables-promising dietary components for the prevention and treatment of cardiovascular disease. Adv. Nutr. 2019, 2, 280-290. [CrossRef] [PubMed]

2. Koryachkina, S.Y.; Ladnova, O.L.; Godunov, O.A.; Kholodova, E.N.; Lazareva, T.N. The study of physiological effect of fruit and vegetable powders in animal experiments. Vopr. Pitan. 2016, 85, 48-56. [PubMed]

3. Tang, G.Y.; Meng, X.; Li, Y.; Zhao, C.N.; Liu, Q.; Li, H.B. Effects of vegetables on cardiovascular diseases and related mechanisms. Nutrients 2017, 9, 857. [CrossRef] [PubMed]

4. Rolnik, A.; Olas, B. Vegetables from Cucurbitaceae family and their products; positive effect on human health. Nutrition 2020, 78, 11078. [CrossRef]

5. Saboo, S.S.; Thorat, P.K.; Tapadiya, G.G.; Khadabadi, S.S. Ancient and recent medicinal use of Cucurbitaceae family. Intern. J. Ther. Applic. 2013, 9, 11-19.

6. Yadav, M.; Jain, S.; Tomar, R.; Prasad, G.B.K.S.; Yadav, H. Medicinal and biological potential of pumpkin: An updated review. Nutr. Res. Rev. 2010, 23, 184-190. [CrossRef]

7. Pastel, S.; Rauf, A. Edible seeds from Cucurbitaceae family as potential functional foods: Immense promises, few concerns. Biomed. Pharmacother. 2017, 91, 330-337. [CrossRef]

8. Montesano, D.; Roccheti, G.; Putnik, P.; Lucini, L. Bioactive profile of pumpkin: An overview on terpenoids and their health-promoting properties. Curr. Opin. Food Sci. 2010, 22, 81-87. [CrossRef]

9. Olas, B. Berry phenolic antioxidants-implications for human health? Front. Pharm. 2018, 9, 78. [CrossRef]

10. Levandi, T.; Püssa, T.; Vaher, M.; Toomik, P.; Kaljurand, M. Oxidation products of free polyunsaturated fatty acids in wheat varieties. Eur. J. Lipid Sci. Technol. 2009, 111, 715-722. [CrossRef]

11. Hamerski, L.; Bomm, M.D.; Silva, D.H.S.; Young, M.C.M.; Furlan, M.; Eberlin, M.N.; Castro-Gamboa, I.; Cavalheiro, A.J.; da Silva Bolzani, V. Phenylpropanoid glucosides from leaves of Coussarea hydrangeifolia (Rubiaceae). Phytochemistry 2005, 66, 1927-1932. [CrossRef] [PubMed]

12. Herrero, M.; Vicente, M.J.; Cifuentes, A.; Ibanez, E. Characterization by high-performance liquid chromatography/electrospray ionization quadrupole time-of-flight mass spectrometry of the lipid fraction of Spirulina platensis pressurized ethanol extract. Rapid Com. Mass Spectrometr. 2007, 21, 1729-1738. [CrossRef] [PubMed]

13. Abu-Reidah, I.M.; Arráez-Román, D.; Quirantes-Piné, R.; Fernández-Arroyo, S.; Segura-Carretero, A.; Fernández-Gutiérrez, A. HPLC-ESI-Q-TOF-MS for a comprehensive characterization of bioactive phenolic compounds in cucumber whole fruit extract. Food Res. Int. 2012, 46, 108-117. [CrossRef]

14. Iswaldi, I.; Gómez-Caravaca, A.M.; Lozano-Sánchez, J.; Arráez-Román, D.; Segura-Carretero, A.; Fernández-Gutiérrez, A. Profiling of phenolic and other polar compounds in zucchini (Cucurbita pepo L.) by reverse-phase high-performance liquid chromatography coupled to quadrupole time-of-flight mass spectrometry. Food Res. Intern 2013, 50, 77-84. [CrossRef]

15. Hamdy, S.A.; El Hefnawy, H.M.; Azzam, S.M.; Aboutabl, E.A. Chemical profiling, volatile oil analysis and anticholinesterase activity of Hydrocotyle umbellata L. aerial parts cultivated in Egypt. S. Afr. J. Bot. 2018, 115, 108-112. [CrossRef]

16. Nowak, P.; Olas, B.; Wachowicz, B. Stres oksydacyjny w przebiegu hemostazy. Post. Biochem. 2010, 3, 239-247.

17. Kim, D.O.; Lee, C.Y. Comprehensive study on vitamin C equivalent antioxidant capacity (VCEAC) of various polyphenolics in scavenging a free radical and its structural relationship. Critic. Rev. Food Sci. Nutr. 2004, 44, 253-273. [CrossRef]

18. Velika, B.; Kron, I. Antioxidant properties of benzoic acid derivatives against Superoxide radical. Free Rad. Antioxid. 2012, 2, 62-67. [CrossRef]

19. Thuan, N.D.; Ha, D.T.; Thuong, P.T.; Na, M.K.; Bae, K.; Lee, J.P.; Lee, J.H.; Seo, H.W.; Min, B.S.; Kim, J.C. A phenylpropanoid glycoside with antioxidant activity from picria tel-ferae. Arch. Pharm. Res. 2007, 30, 1062-1066. [CrossRef] 
20. López-Munguía, A.; Hernández-Romero, Y.; Pedraza-Chaverri, J.; Miranda-Molina, A.; Regla, I.; Martínez, A.; Castillo, E. Phenylpropanoid glycoside analogues: Enzymatic synthesis, antioxidant activity and theoretical study of their free radical scavenger mechanism. PLoS ONE 2011, 6, e20115. [CrossRef]

21. Xanthopoulou, M.N.; Nomikos, T.; Fragopoulou, E.; Antonopoulou, S. Antioxidant and lipoxygenase 554 inhibitory activities of pumpkin seed extracts. Food Res. Int. 2009, 42, 641-646. [CrossRef]

22. Khennouf, S.; Amira, S.; Arrar, L.; Baghiani, A. effect of some phenolic compounds and quercus tannins on lipid peroxidation. World Appl. Sci. J. 2009, 8, 1144-1149.

23. Torkova, A.A.; Lisitskaya, K.V.; Filimonov, I.S.; Glazunova, O.A.; Kachalova, G.S.; Golubev, V.N.; Fedorova, T.V. Physicochemical and functional properties of Cucurbita maxima pumpkin pectin and commercial citrus and apple pectins: A comparative evaluation. PLOS ONE 2018, 13, e0204261. [CrossRef] [PubMed]

24. Shayesteh, R.; Kamalinejad, M.; Adiban, H.; Kardan, A.; Keyhanfar, F.; Eskandari, M.R. Cytoprotective effects of pumpkin (Cucurbita moschata) fruit extract against oxidative stress and carbonyl stress. Drug Res. 2017, 67, 576-582. [CrossRef] [PubMed]

25. Bahramsoltani, R.; Farzaei, M.H.; Abdolghaffari, A.H.; Rahimi, R.; Samadi, N.; Heidari, M.; Esfandyari, M.; Baeeri, M.; Hassanzadeh, G.; Abdollahi, M.; et al. Evaluation of phytocehmicals, antioxidant and burn wound healing activities of Cucurbita muschata Duchesne fruit peel. Iran. J. Basic Med. Sci. 2017, 20, 798-805.

26. Abarikwu, S.O.; Mgbudom-Okah, C.J.; Onuah, C.L.; Ogunlaja, A. Fluted pumpkin seeds protect against busulfan-induced oxidative stress and testicular injuries in adult mice. Drug Chem. Toxicol. 2019, 30, 1-11. [CrossRef]

27. Ghahremanloo, A.; Hajipour, R.; Hemmati, M.; Moossavi, M.; Mohagiq, Z. The beneficial effects of pumpkin extract on atherogenic lipid, insulin resistance and oxidative stress status in high-fat diet-induced obese rats. J. Complement. Integr. Med. 2017, 24, 1-11. [CrossRef]

28. Lis, B.; Jedrejek, D.; Stochmal, A.; Olas, B. Assessment of effects of phenolic fractions from leaves and petals of dandelion in selected components of hemostasis. Food Res. Int. 2018, 107, 605-612. [CrossRef]

29. Whitaker, J.R.; Granum, P.E. An absolute method for protein determination based on difference in absorbance at 235 and $280 \mathrm{~nm}$. Anal. Biochem. 1980, 109, 156-159. [CrossRef]

30. Bradford, M.M. A rapid and sensitive method for the quantitation of microgram quantities of protein utilizing the principle of protein-dye binding. Anal. Biochem. 1976, 72, 248-254. [CrossRef]

31. Wachowicz, B. Adenine nucleotides in thrombocytes of birds. Cell Biochem. Funct. 1984, 2, 167-170. [CrossRef] [PubMed]

32. Bartosz, G. Druga Twarz Tlenu: Wolne Rodniki w Przyrodzie; Wydawnictwo Naukowe PWN: Warszawa, Poland, 2008.

33. Levine, R.L.; Garland, D.; Oliver, C.N.; Amici, A.; Climent, I.; Lenz, A.-G.; Ahn, B.-W.; Shaltiel, S.; Stadtman, E.R. Determination of carbonyl content in oxidatively modified proteins. Methods Enzymol. 1990, 186, 464-478.

34. Ando, Y.; Steiner, M. Sulfhydryl and disulfide groups of platelet membranes. I. Determination of sulfhydryl groups. Biochim. Biophys. Acta Biomembr. 1973, 311, 26-37. [CrossRef]

35. Ando, Y.; Steiner, M. Sulfhydryl and disulfide groups of platelet membranes. II. Determination of disulfide groups. Biochim. Biophys. Acta Biomembr. 1973, 311, 38-44. [CrossRef]

36. Cieśla, Ł.; Kowalska, I.; Oleszek, W.; Stochmal, A. Free radical scavenging activities of polyphenolic compounds isolated from Medicago sativa and Medicago truncatula assessed by means of thin-layer chromatography DPPH• rapid test. Phytochem. Anal. 2013, 24, 47-52. [CrossRef] [PubMed]

37. Kowalska, I.; Jędrejek, D.; Cieśla, Ł.; Pecio, Ł.; Masullo, M.; Piacente, S.; Oleszek, W.; Stochmal, A. Isolation, chemical and free radical scavenging characterization of phenolics from Trifolium scabrum L. aerial parts. J. Agric. Food Chem. 2013, 61, 4417-4423. [CrossRef]

38. Kowalska, I.; Cieśla, Ł.; Oniszczuk, T.; Waksmundzka-Hajnos, M.; Oleszek, W.; Stochmal, A. Comparison of two TLCDPPH-image processing procedures for studying free radical scavenging activity of compounds from selected varieties of Medicago sativa. J. Liquid Chromatogr. Relat. Technol. 2013, 36, 2387-2394. [CrossRef]

39. Olech, M.; Komsta, Ł.; Nowak, R.; Cieśla, Ł.; Waksmundzka-Hajnos, M. Investigation of antiradical activity of plant material by thin-layer chromatography with image processing. Food Chem. 2012, 132, 549-553. [CrossRef] 
40. Hu, R.; Dunmire, K.M.; Truelock, C.N.; Paulk, C.B.; Aldrich, G.; Li, Y. Antioxidant performances of corn gluten meal and DDGS protein hydrolysates in food, pet food, and feed systems. J. Agric. Food Res. 2020, 2, 100030. [CrossRef]

41. Mesa, M.D.; Olza, J.; Gonzalez-Anton, C.; Aguilera, C.M.; Moreno-Torres, R.; Jimenez, A.; Perez de la Cruz, A.; Ruperez, A.I.; Gil, A. Changes in Oxidative Stress and Inflammatory Biomarkers in Fragile Adults over Fifty Years of Age and in Elderly People Exclusively Fed Enteral Nutrition. Oxidative Med. Cell. Longev. 2016, 5709312. [CrossRef] [PubMed]

42. Malinowska, J.; Kołodziejczyk-Czepas, J.; Moniuszko-Szajwaj, B.; Kowalska, I.; Oleszek, W.; Stochmal, A.; Olas, B. Phenolic fractions from Trifolium pallidum and Trifolium scabrum aerial parts in human plasma protect against changes induced by hyperhomocysteinemia in vitro. Food Chem. Toxicol. 2012, 50, 4023-4027. [CrossRef] [PubMed]

Sample Availability: Samples of pumpkin (Cucurbita pepo; fruit), zucchini (Cucurbita pepo convar. giromontina), cucumber (Cucumis sativus), white pattypan squash (Cucurbita pepo var. patisoniana) and yellow pattypan squash (Cucurbita pepo var. patisoniana) are available from the authors.

(C) 2020 by the authors. Licensee MDPI, Basel, Switzerland. This article is an open access article distributed under the terms and conditions of the Creative Commons Attribution (CC BY) license (http://creativecommons.org/licenses/by/4.0/). 